feeling produced a mutual smile. So the motion for non-splinting was carried at once. She was much extenuated, and to defend the parts from pressure, knowing that she would have to lie on the affected side for a long period, and to restrain the parts gently in apposition, a large and soft plaster, spread with emplast. lithargyri, was applied over the site of the fracture, which partially embraced the limb. She suffered much pain, and to relieve it was supplied with half-grains of gum. opii, in pills, which were taken at night; and when such pills are recently made, with all due deference, I think they are better (for the patient, at least), than the pompons officinal preparation of opium, with fossil alkali and oil, and what else we do not exactly know. Besides these pillo she took castor-oil occasionally, in the morving, or infus. sennre, to obviate costiveness. At length her pains were moderate, and she could lay quiescent in bed, and passed the winter.

The idea of her walking again was scarcely entertained, but what was my surprise, one fine day, to overtake her, slowly pacing down the street, on the paralytic side supported by a female, and on the side of the fractured limb her hand leaned on the "crummock." I was curions to observe that her legs were of the same length as she stood upright on the ground, and her neat little foot was pointed as properly as the other. I have seen her walk more than once since. She is alive, and is now more than 73 years of age.

In Mr. Bryant's case the bone was split, therefore a restoration, perhaps, could not take place. Mr. Symes, a surgeon, of Edinburgh, refers to such cases in his synoptical work of two volumes, for students; and Mr. Dendy is assured that no constraint was imposed on either of the two last-mentioned cases, - no pelvic straps, nor restraint of any sort, more than that of a plaster, but each of these poor old folks indulged their aged limbs upon a soft feather bed, at their humble abodes, and there slowly recovered-perfectly recovered; but a very different result would most certainly have followed, if the feather bed had been supplanted by the harci mattrass of a hos. pital.

In concluding, I must take the opportunity of thanking Mr. Crisp for his recommendation at the Medical Society before alluded to, "that Mr. Radley's plan should be tried before decided on; for he had seen cases in the hospital that would have done better without splints than with them." How opposite this remark to that of the famous hospital surgeon, who philosophically said he thought that crooked legs wonld follow the non-employment of splints, and therefore would not make the experiment!
Finally, I beg to say, that any opinion on the subject, which is given without the previous employment of full, fair, and rigid tests, and subjected to proof in practice, are mere postulations, airy hypotheses, which are unworthy of adoption after the evidence which has now been laid before the profes. sion on behalf of the new mode of treat. ment.

\section{IMPROVED MODE OF REDUCING ARSENIOUS ACID.}

To the Editor of 'Tue Lancet.

Srr:-I beg to submit to your notice the following observation on the reduction of arsenious acid by the flame of hydrogen gas, which appears to me to be a useful improvement on the method invented by Mr. Marsh. In the experiments which have hitherto been conducted, the gas has been allowed to escape upwards, by means of a straight tube, and the crust of metallic arsenic has been deposited upon a plate of glass, held immediately over the flame. By this process the arsenuretted hydrogen is rapidly dispersed, carrying with it a great deal of the metallic arsenic unreduced; consequently, a small portion only is col. lected on the plate of glass; but if the plan which I have adopted be resorted to, a much greater quantity of the gas may be collected, and the decomposition is rendered more obvious.

This method consists simply in the em. ployment of a tube, bent twice, at right angles, of which the extremity is to be firmly luted into the bottle containing the materials for hydrogen gas and the solution of arsenious acid. When the gas is passing over briskly, a light is to be applied to the free extremity. In a few minutes that $\mathrm{ex}$ tremity will be completely coated with the metal. In this manner a tube, of the diameter of an ordinary quill, may be encrusted, to the extent of a $\frac{3}{4}$ of an inch, by five drops of the cold boiled solution of arsenious acid. The advantage of this method is obviously to preserve as much as possible of the metal, a great part of which is dissipated with the gas when the straight tube is employed. In the curved tube, on the contrary, the gas will continue to burn with a slow lam. bent flame for a long period, and gradually deposit the metal upon its inner and outer surfaces. The vitreous appearance of the free extremity is completely destroyed, and that portion of the tube resembles a pewter or leaden pipe. I have the hononi to be, Sir, your obedient servant,

\section{G. A. F. Wilks, M.D.,}

Lecturer on Materia Medica and Botany in the North Lon. School of Med., \&c.

\section{5, Hart-street, Bloomsbury,}

Nov. 27, 1838. 